\title{
Application of Customer Satisfaction Servicing in the Social Functions of universities
}

\author{
Yuru Wang \\ Business College,Zhengzhou Huaxin University,Zhengzhou,451100,China \\ email:duoduo7999@sina.com
}

Keywords: Customer; Customer Satisfaction; Universities; Service

\begin{abstract}
It is the new trend of the modern university management research to use customer satisfaction strategy in university management. This article is to study how to establish customer satisfaction evaluation system of university social service functions. Analysis the customer types of universities ; study the content and features of customer satisfaction in university social services; evaluating on customer satisfaction and pointing out that we should establish the college customer satisfaction evaluation organization, the evaluation and weight data collection and scientific analysis, establishing and improving the feedback system and supervision mechanism basing on the evaluation results.
\end{abstract}

\section{Introduction}

Customer satisfaction is the business strategy of an enterprise. It aims to make customers completely satisfied with their products or services. The entire enterprise integrates to improve the quality of products, services and a corporate culture, basing on the scientific measurement of the degree of customer satisfaction according to the results of the investigation and analysis. It insists on customer-oriented service standards in order to make the customer satisfied and achieve sustained growth in enterprise efficiency. It has an important theoretical and practical significance for improving college social services and the quality of education to research customer satisfaction strategy in our colleges and universities to serve the community functions.

\section{Universities Customer Definition}

Accordance to the definition of GB/T1900-2000, customers are the organizations or individuals to accept the products and services.[2] Business is a customer-driven organization. The basic operating guidelines for the management are customer first and customers as God. Respect for the customer and the pursuit of customer satisfaction are the basic rules of today's business management and competition.[1] The management of college social service functions is affected by the original planned economy, and to a large extent, education department is in charge of administrative power appendage, society's supervision and restraint for universities are not sensitive and automatical as for market mechanism. Most colleges and universities are still vague on customer service.

The latest public management theory says that the government is no longer override authority over the society, but social services organization.[5] As the government appendage, the universities should take the initiative to take up the necessary services social functions. Colleges and universities should meet the college customer needs and provide high-quality and high-performance services. Citing customer satisfaction management concepts into the college management has a major impact on university functions, service performance and quality of personnel training, this is the most important reason to put customer orientation into the college of management.For colleges and universities,the customer is the object of its object and management services. The recognition and trust of these customers for universities depend on the customer satisfaction for universities. The author thinks that the customers for colleges and universities refer to college products and 
services users. The products and services of the university refer to college-trained people, teaching scientific research, technological achievements, external service providing by college education resources. Therefore, the government sector customers can be divided into three levels. First of all is the government. It is not only the higher levels of government departments giving college administrative powers and duties but also the base of university personnel training, the important users of teaching scientific research, the major players of the university management. Second, enterprises and institutions are the main location for university personnel training, and the applicants of teaching scientific research. Third, the educators, they are the basis of the college. Fourth, they are the public. Because the strong external spillovers of higher education resources, their products and services have an important role to improve the level of education and the overall quality, the community should be the ultimate object of the college social service. Therefore, our colleges and universities must be highly focused on the customer, must always correctly identify the needs of the customer and the customer and to carry out customer satisfaction surveys focusing on the customer feel if they are to meet their requirements.

\section{Features of Universities Customer Satisfaction}

Customer satisfaction is the customer's requirements are met to the degree of feelings in the customer mind. Satisfaction is a psychological concept and a positive state of mind. This state is to stimulate people's expectations are met and desirable due to a need or outside certain.[3] Universities customer satisfaction refers to the satisfaction with the products and services of the college and the college product service. The college is different from the enterprises, universities customer satisfaction have the following characteristics.

A.Higher Education regularity resulting in the formation of customer satisfaction accumulation.

The university is the commitment and organizers of higher education. They are not only society organizations of the training of highly qualified personnel and the scientific research, but also they charges with the important functions of social services and cultural heritage. The college runs differently from the enterprise management, higher education has its own rule. Personnel training, scientific research, the application circle of the results are longer. College education goes through for about four years, they have at least 1-2 years of scientific research, as long as 3-5 years. Particularity of higher education products and services makes the users of its products and services have hysteresis characteristics of its evaluation. Furthermore, the use and effect of college products and services feedback also have a certain period of time. Customer satisfaction also need to dissemination to the formation of a long-time customer base.

B.University categories resulting in the otherness of customer satisfaction.

Due to the role of the internal and external factors, the various functions of the colleges and universities play in varying degrees. Extremely unbalanced developments are between universities. Universities category features are obvious. Currently, there are Public and Private Colleges from the nature of points; colleges, undergraduate colleges and universities from the level; research, teaching and research, research and teaching, and teaching from the function; integration, Science and Engineering, grammar Normal, medical, arts, sports, and other colleges and universities from major layout. Undergraduate institutions, in terms of the length of time from the educational point of view, there is a new class of undergraduate institutions. Different customers of different types of colleges and universities, it is inevitable to have the differences of customer satisfaction. We should take into account the differences between the colleges on evaluation of customer satisfaction for government services.

C.Customer diversity resulting in multilevel nature of customer satisfaction.

The customers of the college are multifaceted, including the government, enterprises and institutions, the educated, the average citizen, and so on. The different interests of all walks of life need to have specific interests and demands of the various interest groups. Because of the different interests of all ranks, the various interest groups have specific interests and demands. Colleges and universities should be concerned about the interests of the various types of customers, reasonably deal with interest, should take into account the different requirements of the different levels of 
customer service to the college testing, evaluation and supervision of customer satisfaction, improve customer satisfaction evaluation targeted and science.

\title{
Customer Satisfaction Evaluation of Colleges and Universities
}

\author{
A.Establishment of the Higher Education Customer Satisfaction Evaluation of Social \\ Organization
}

It is can be determined by the higher education colleges' competent department or university organization and to be responsible for customer satisfaction evaluation of a regional or university. Assessment of the organization studies and formulates relevant customer satisfaction index system and regularly or irregularly organized relevant experts and scholars, education director departments, customer representatives to carry out a comprehensive evaluation or special evaluation of the Higher Education Customer Satisfaction. Starting to evaluate the organization from the overall interests of society rather than starting from a customer base of interest groups, objective, fair and scientific evaluation process to ensure the decision-making consulting services for university development.

B.Determine customer satisfaction indexes and index weights.

Customer satisfaction degree is a measure of the indicators of the customers of a product and service satisfaction.[4] According to the meaning of customer satisfaction, customer satisfaction is the degree of difference between the subjective feelings of their anticipated expectations customers of a product and service. Due to judgment and other factors, some customers judge errors inevitably. The indicator design requires some objective quality indicators to avoid relying solely on the subjective measure of deviation. Overall, customer satisfaction indicators should include the following five main areas: First, the scale and effectiveness of educational resources. College education resources include land, buildings, teachers, teaching equipment, books, living facilities, the scale of the educational resources through land, construction area , the number and structure of teachers, teaching instrument equipment value or number of sets of station, the collection of books, electronic books amount to its performance through educational resources students mean, the education resource usage and update rate, building useful life, teaching equipment maintenance rate, efficiency in the use, borrow books the number of books views reflect. Second, the graduates' quality. Mainly embodied by the employment rate of graduates, their counterparts in the employment rate, entrepreneurship rate, the average annual income of graduates, the rate of job stability, employing units talent evaluation. Third, teaching scientific research and application efficiency. Mainly include the quantity of teaching scientific research, quality and application of the results generated by the social and economic benefits; key indicators, including the number of core papers, the results of the original rate, the conversion rate of the outcome, the outcome of the application effectiveness. Fourth, the campus culture. Campus environment, campus greening, academic atmosphere, the degree of democratization of the management, the council of the school situation openness. Fifth, other indicators of reflecting customer satisfaction. Such as: the level of tuition fees, the education level of benefit, visibility, and honorary degrees.

According to customer needs analysis to determine customer satisfaction indicators and establish customer satisfaction function.

$F=F\left(\sum C_{i} T_{i}\right)=F\left(C_{1} T_{1}+C_{2} T_{2}+\ldots+C_{n} T_{n}\right)$

$C_{i}(i=1,2, \ldots n)$ is the degree of satisfaction of the customer $i$ indicators, $T_{i}(i=1,2, \ldots n)$ is the weight of the first $i$ indicators, $\Sigma T_{i}=1$.

C.University information collection and analysis of customer satisfaction.

Information Collection. in order to more fully reflect the true wishes of the customer, the colleges must make more customers promote broad participation in order to seek the views of as many customers as possible. Generally mainly through investigation and statistics information collection, the survey method can take the survey, network surveys, interview surveys, telephone surveys and other forms. Statistical method is to regularly collect information and data summary. Statistics evaluation organization puts yourself standing in the customer 's position and 
understanding of the indicators of the reliability of the information, accuracy regularly assessing organizational customer satisfaction assessment of college. Understanding and analysis of the satisfaction universities of college customers, as well as a variety of emerging new demand , timely detection of existing educational products and services, strengths and weaknesses in the quality and effectiveness for the college to provide educational products, improve the quality of decisionmaking basis, thereby increasing customer satisfaction.

Information Analysis. Qualitative analysis: Through customer satisfaction surveying, statistical information analysis, synthesis, comparison, abstraction and generalization, clear the intrinsic relationship between the individual satisfaction index and find the main reasons of customers universities satisfaction or dissatisfaction. Qualitative analysis of the main virtue of the subjective experience of the evaluators, professional competence, with the existing information, the characteristics of the Higher Education Customer Satisfaction, developments and changes in the law to make judgments evaluators to have literacy and the ability of the expert. Quantitative analysis:Quantitative analysis of the number of characteristics of the original data, the analysis of the relationship between the number of changes to the number of the given quantitative evaluation of the university management, through the description and analysis of the "quantity". Quantitative methods are more scientific, but require higher deep knowledge of mathematics, and qualitative methods, though are more rough, it can be used without enough insufficient data or analysis and mathematical foundation. Qualitative analysis methods can not abandon the mathematical tools , quantitative analysis must be based on the qualitative prediction. The two complement are in combination with each other. And finally on the basis of these analyzes, the colleges improve their customer satisfaction improvements.

\section{Feedback System and Oversight Mechanism}

Generally speaking, due to the strong dependence on the government and education authorities, the universities can form strong administrative system of higher education. It results in the condition that the majority of colleges and universities pay little attention to its products and services to achieve customer satisfaction. It is closely related to the supervision mechanism and the lack of customer satisfaction feedback. Therefore, the establishment of a feedback system and supervision mechanism can really play an effective role in customer satisfaction evaluation.

First, feedback system adhering to the "feedback": feedback to colleges evaluated, its higher authorities and the public.Evaluation of customer satisfaction has a good role in promoting the colleges and universities to improve their work and services. Customer satisfaction survey can make the quantitative evaluation of university products and quality of service. It can analyses and judge the product and the main problems in the service. Moreover, system reflect the evaluation results to the universities evaluated and higher authorities after evaluating customer satisfaction and promptly announced to the public. Colleges and universities evaluated can improve their services according to the assessment results to reach the customer satisfaction and maintain customer satisfaction levels.

Second, strengthen the legal construction of the higher education customer satisfaction.China has not yet formed the laws and regulations that are corresponding with the college customer satisfaction. Colleges and universities lack sufficient power or pressure to measure its customer satisfaction. They will not take the initiative to accept the social evaluation, and also lack of a unified and standardized implementation of standards of customer satisfaction measurement. Therefore, the development of appropriate laws and regulations and the establishment of effective supervision and management mechanism are to build a strong guarantee for the Customer Satisfaction Index of Chinese Universities.

Evaluation of customer satisfaction provides a solution to improving the functions of colleges and universities. The customer satisfaction rating of products and services provided by universities monitors and improves the college functions and provides better and higher education for the public and social service. 


\section{References}

[1] Philip Kotler,Thmas Hayes,Paul N.Bloom.Marketing Professional Services[M],2ed.,Prentice Hall Direct,2002.

[2] Liu Yu.Measurement of Customer Satisfaction[M].Social Sciences Academic Press,2003.

[3] Ji Xiaoyi,Huang Xiaoping.Testing and Appraising of Customers' Satisfaction Degree in Higher Education Institutions[J].Higher Education Development and Evaluation,2005(7):29-32.

[4] Na Jianfei,Xiong Zhijian.On the Construction of Customer Satisfaction Degree Evaluation System[J]. World Standardization \& Quality Management,2002(6).

[5] Chen Zhenming.The Government Reengineering:Western New Public Management Review[M]. China Renmin University Press,2003. 